Annals of International Medical and Dental Research

E-ISSN: 2395-2822 | P-ISSN: 2395-2814

Vol-8, Issue-2 | March-April 2022

DOI: $10.53339 /$ aimdr.2022.8.2.8

Page no- 43-51 | Section- Research Article (Radiodiagnosis)

\title{
Novel biomarkers for Diagnosis of Pulmonary Tuberculosis and Tuberculous Pleural Effusion
}

\author{
Eman Alsayed Abouahmed ${ }^{*}$, Samar Mansour ${ }^{2}$, Ali Omar Abdelaziz ${ }^{3}$, Naglaa M Farag4
}

\begin{abstract}
${ }^{1}$ Clinical Pathology Department, Faculty of Medicine, Minia University, Minia, Egypt. Email: Emanlab2003@yahoo.com,

Orcid ID: 0000-0002-6220-846X

${ }^{2}$ Clinical Pathology Department, South Egypt Cancer Institute,Assiut University, Assiut, Egypt. Email ID: smsemhms@yahoo.com Orcid ID: 0000-0002-1099-9167

${ }^{3}$ Chest Department, Minia faculty of medicine, Minia university, Egypt.

Email ID: omran282@yahoo.com,

Orcid ID: 0000-0003-4325-6412

${ }^{4}$ Medical Biochemistry Department, Alexandria faculty of medicine, Alexandria university, Egypt.

Email: ehab.khalifa@dartalamedical.com,

Orcid ID: 0000-0003-2579-3580

*Corresponding author
\end{abstract}

Received: 30 November 2021

Revised: 06 January 2022

Accepted: 17 January 2022

Published: 18 February 2022

\begin{abstract}
Background: The present study aimed to evaluate the importance of serum, pleural adenosine deaminase (ADA), and Gene Xpert in Diagnosis of TB and TB Pleural Effusion (TB-PLE.).Material \& Methods:The study was done with $75 \mathrm{~TB}$ cases, 50 cases of them were diagnosed as Pulmonary TB and 25 cases as TB pleural effusion, collecting also 50 nonTB pleural effusion, Malignant and acute bacterial infection comprise 21 and 29 cases respectively. Cases with transudative pleural effusion were excluded from the study. Finally, 75 were healthy control group.Results:There was a highly significant difference between the mean age of TB-PE Patients and Patients non-TB-PLE (P-value <0.001), while there was a non-significant difference with patients with P-TB (P-value $>0.05$ ). Mean of Serum ADA level were highest 53.16 U/L in TB-PE cases, shown to be statistically significant when compared to $43.2 \mathrm{U} / \mathrm{L}$ in P-TB and $25.4 \mathrm{U} / \mathrm{L}$ in non TBpleural effusion. With p-value of 0.02 and 0.001 respectively.Conclusions:We concluded that GeneXpert can be a useful diagnostic method in patients with suspected pulmonary tuberculosis. Serum and pleural fluid ADA level is a very helpful test to rule out a TB and can help differentiate tubercular etiology from nontubercular.
\end{abstract}

Keywords:-TB, Pleural Effusion, pleural ADA, GeneXpert.

\section{INTRODUCTION}

It is important to consider the possibility of tuberculous pleuritis in all patients with an undiagnosed pleural effusion.[1]

Some researchers believe that the pleural ADA levels of more than $70 \mathrm{IU} / \mathrm{L}$ is required for the diagnosis of TB-PLE, while a level less than 40 IU/L actually ruled out TB-PLE.[2] Several factors may affect the pleural fluid ADA levels in patients with TB-PLE. Among these factors are prevalence of tuberculosis, race of studied population, age and immune status of the patients.[3]

Pleural fluid cyto-analysis, pleural protein and lactate dehydrogenase (LDH) may also affect the ADA levels in patients with TB-PLE.[4] ADA is essential for proliferation and differentiation of lymphoid cells, especially $\mathrm{T}$ cells. ADA seems to be an index for cellular immunity.[5] 
Annals of International Medical and Dental Research

E-ISSN: 2395-2822 | P-ISSN: 2395-2814

Vol-8, Issue-2 | March-April 2022

DOI: 10.53339/aimdr.2022.8.2.8

Page no- 43-51 | Section- Research Article (Radiodiagnosis)

Nowadays measurement of ADA levels is the gold standard for the diagnosis of tuberculous pleural effusion in developing countries. [6]

More recently, WHO endorsed the GeneXpert(1) for the diagnosis of TB.[7] Gene Xpert MTB/RIF is cartridge-based nucleic acid amplification test having fully integrated and automated amplification and detection using real time polymerase chain reaction (PCR), providing result within 2 hours. It is a highly specific test as it uses 3 specific primers and 5 unique molecular probes to target RpoB gene of mycobacterium tuberculosis (MTB). [7] Because of its rapidity, simplicity, accuracy and sensitivity of GeneXpert MTB/RIF technology is emerging as a novel and promising technique to diagnose tuberculous effusion. [8] Patients with high risk of tuberculosis like presumptive HIV-associated TB patients and pediatric presumptive including extra pulmonary cases in whom AFB smear examination is usually negative, are the most likely to be benefited from GeneXpert.[]

\section{MATERIAL AND METHODS}

The study included clinico-radiologically and pathologically suspected patients of TB and exudative pleural effusion, admitted in Prince Mishari Bin Saud Hospital in Albah, Saudi Arabia started since 2017 for a period of two years, and the study population was adults > 12 years old with 75 TB cases. Among TB cases, there were 50 cases of Pulmonary TB, 25 cases of TB pleural effusion and 50 were non TB pleural effusion, Malignant and acute bacterial infection comprise 21 and 29 cases respectively. Cases with transudative pleural effusion were excluded from the study.
The study was approved by our hospital review board, Prince Mishari Ethical Committee of Human research, (Reference No. EA /SR/06-04/17/0003), and written informed consent was obtained from patient's family.

\section{$\underline{\text { Inclusion criteria }}$}

1. Patients having clinical feature of TB and tubercular pleural effusion.

2. Pleural effusion on chest $X$ - ray and ultrasonography.

3. Exudative pleural effusion by Light's criteria (effusion protein/serum protein ratio greater than 0.5 and effusion $\mathrm{LDH} /$ serum $\mathrm{LDH}$ ratio greater than 0.6), [?] lymphocytic predominant and ADA more than 30unit/litre.

A sample size of 210 patients was calculated based on a power of $80 \%$ and a significant level of 0.05 to detect $30 \%$ difference in flank pain scores and $26 \%$ difference in frequency scores in the first 2 weeks with the stent in situ.[]

\section{Exclusion criteria}

1. Transudative pleural effusion.

2. Patients with well documented chronic history of heart failure, nephrotic syndrome, liver cirrhosis.

3. Cases with thoracic empyema.

4. Contraindications to thoracocentesis, like patient on mechanical ventilation, uncooperative patients, bleeding diathesis, patient on anticoagulation therapy.

5. Patients on anti-tuberculous treatment.

Pleural tap was under taken, $30 \mathrm{~mL}$ of fluid in a heparin-treated syringe and transferred to laboratory for analysis. Each sputum and Pleural tap samples received in the lab were 
Annals of International Medical and Dental Research

E-ISSN: 2395-2822 | P-ISSN: 2395-2814

Vol-8, Issue-2 | March-April 2022

DOI: 10.53339/aimdr.2022.8.2.8

Page no- 43-51 | Section- Research Article (Radiodiagnosis)

divided into five parts; one part was immediately tested using GeneXpert, second part used for ZN smear microscopy, third part for TB culture on LJ and performed on same day, the fourth for chemical tests and ADA and the fifth part for hematopatholologic examination (cell count, cell type, malignant cells).

For Gene Xpert MTB / RIF test, The fluid was centrifuged at $3000 \mathrm{rpm}$ for 15 minutes, Lysing agent was added to the sediment. Later on, $2 \mathrm{ml}$ sediment was transferred to Gene Xpert cartridge and results were obtained within 2 hours.[1]

Determination of serum(S) - and pleural (P)ADA from the cases and control was done by Cobas by Diazyme kit on COBAS 6000.

\section{Statistical Analysis}

The data was tabulated in Microsoft excel spreadsheet in a master chart and studied for correlation. Stastical analysis of the data was conducted with stastical package for the social science system version SPSS17.0. Sensitivity, specificity, PPV and NPV was calculated.

Mean differences between groups were analyzed using student $t$ test and One-Way ANOVA (Tukey test).

Youden index was used to define usefulness and overall benefit of optimal cut off point of the ADA levels in diagnosis of tuberculosis pleural effusion. Any value below 50\% denote an overall lack of the diagnostic test to detect either disease or health
Pearson correlation coefficient was used for defining correlation between ADA and independent variable.

$\mathrm{P}$ value of $<0.05$ was considered to be statistically significant.

\section{RESULTS}

A total 200 cases, 75 were healthy control group and 75 were TB cases (50 of them were Pulmonary P-TB, 25 cases is TB-PLE) and 50 were non TB-PLE (Malignant and acute bacterial infection comprise 21 and 29 cases respectively).

Ten patients were excluded from the final analysis: three had incomplete clinical data and seven were on anti-TB treatment for more than 48 hours prior to the samples being taken. There was high significant difference between mean age of TB- PE Patients and Patients non TB-PLE (P value <0.001), while there was nonsignificant difference with patients with P-TB ( $\mathrm{P}$ value $>0.05)$.

Mean of Serum ADA level were highest 53.16 $\mathrm{U} / \mathrm{L}$ in TB-PE cases, shown to be statistically significant when compared to $43.2 \mathrm{U} / \mathrm{L}$ in P-TB and 25.4 U/L in non TBpleural effusion .with $\mathrm{p}$ value of 0.02 and 0.001 respectively.and also shown to be higher than Healthy control cases of $19.5 \mathrm{U} / \mathrm{L}$. This variation in Mean of P-TB and TB-PLEwere shown to be statistically significant with $\mathrm{p}$ value of $0.008,0.001$ respectively.

Although in the present study serum ADA levels in non- tubercular pleural effusion were higher as compared to healthy controls but not statistically significant (p 0.06). 
Annals of International Medical and Dental Research E-ISSN: 2395-2822 | P-ISSN: 2395-2814

Vol-8, Issue-2 | March-April 2022

DOI: 10.53339/aimdr.2022.8.2.8

Page no- 43-51 | Section- Research Article (Radiodiagnosis)

Mean of pleural ADA level was high $96.52 \mathrm{U} / \mathrm{L}$ in TB-PE cases and was shown to be statistically significantly different from mean level of non TB pleural effusion 34.9 U/L with $P$ value of 0.0009 .

Mean of pleural ADA level in TB-PE and non TB pleural effusion cases was shown to be higher and statistically significantly different from mean level of serum ADA level in the same cases with $p$ value of $0.002,0.005$ respectively [Table 1].

The variation of Mean S- ADA level among male and female was found statistically significant with $\mathrm{p}$ value of 0.028 . Male subjects were more prone to P-TB (4.67:1 male to female) and pleural effusion was higher in males than females $54(72.0 \%)$ males and 21 $(28.0 \%)$. [Table 1].

A total of 200 respiratory specimens (75 pleural and 125 Sputum samples) were tested. 92 samples (46.0\%) (19 pleural and 73sputum) were GeneXpert TB positive, 86 samples (43.0\%) (17 pleural and 69 sputum) were culture TB positive.78 samples (39.0\%) (11 pleural and 67sputum) were culture TB and GeneXpert positive, isolates were found to belong to MTB. While the remaining eight (4\%) cases are negativeGeneXpert positive TB culture were identified as Mycobacterium other than tuberculosis (MOTT) species. Further speciation of these isolates was not done and 14 cases are positiveGeneXpert negative TB culture [Table 3].

By taking culture method as reference, samples that were positive and negative in culture were considered true positive and true negative. Culture negative and GeneXpert positive samples were taken as false positive samples. GeneXpert negative and culture positive samples were considered false negative.

There was a significant positive correlation between MTB detected patients by Gene Xpert and ADA value $(\mathrm{r}=0.89, \mathrm{p}<0.05)$, and similarly significant positive correlation was also seen with MTB detected patients and lymphocyte count $(\mathrm{r}=0.91, \mathrm{p}<0.05)$ [Table 5].

Table 1:Demographic data of ADAU/L, SEX and AGE

\begin{tabular}{|c|c|c|c|c|c|c|c|}
\hline \multirow[t]{3}{*}{ Study Group } & \multirow{3}{*}{$\begin{array}{l}\text { Age (years) } \\
\text { Mean } \pm \text { SD }\end{array}$} & \multicolumn{3}{|c|}{ S- ADA U/L } & \multicolumn{3}{|c|}{ P-ADA U/L } \\
\hline & & \multirow{2}{*}{ Mean \pm SD } & \multicolumn{2}{|c|}{ Sex } & \multirow{2}{*}{$\begin{array}{c}\text { Mean } \pm \\
\text { SD }\end{array}$} & \multicolumn{2}{|c|}{ Sex } \\
\hline & & & Male & Female & & Male & Female \\
\hline $\begin{array}{l}\text { P-TB } \\
(\mathrm{N}: 50)\end{array}$ & $41.10 \pm 9.14$ & $43.2 \pm 17.9$ & --------- & ---------- & ----------- & 41 & 9 \\
\hline $\begin{array}{l}\text { TB- PE } \\
(\mathrm{N}: 25)\end{array}$ & $34.31 \pm 7.53$ & $53.16 \pm 12.65$ & ---------- & ---------- & $\begin{array}{l}96.52 \pm \\
21.5\end{array}$ & 21 & 4 \\
\hline $\begin{array}{l}\text { Non TB-PE } \\
(\mathrm{N}: 50)\end{array}$ & $46.70 \pm 6.14$ & $25.4 \pm 26.3$ & ---------- & ---------- & $\begin{array}{ll}34.9 & \pm \\
19.3 & \\
\end{array}$ & 33 & 17 \\
\hline $\begin{array}{l}\text { Control } \\
(\mathrm{N}: 75)\end{array}$ & $31.71 \pm 4.51$ & $19.5 \pm 11.8$ & ---------- & ----------- & ------------ & 48 & 27 \\
\hline & & & $43.61^{*}$ & $33.49 *$ & & & \\
\hline & & & & 0.028 & & & \\
\hline
\end{tabular}

Copyright: (-The author(s), published in Annals of International Medical and Dental Research, Vol-8, Issue-2. This is an open access article under the Attribution-NonCommercial 2.0 Generic (CC BY-NC 2.0) license. (https://creativecommons.org/licenses/by-nc/2.0/) 
Annals of International Medical and Dental Research E-ISSN: 2395-2822 | P-ISSN: 2395-2814

Vol-8, Issue-2 | March-April 2022

DOI: 10.53339/aimdr.2022.8.2.8

Page no- 43-51 | Section- Research Article (Radiodiagnosis)

Table2:Biochemical Parameter, P-ADA Levels and Cell Count (WBC) in Pleural Fluid (TB-PLE vs Non TB-PLE)

\begin{tabular}{|l|l|l|l|}
\hline Pleural Fluid Parameter & TB-PLE & Non TB-PLE & P Value \\
\hline P-ADA, IU/L & $96.52 \pm 21.5$ & $34.9 \pm 19.3$ & $* 0.001$ \\
\hline Sugar, mg/dL & $86.4 \pm 36.1$ & $109.5 \pm 45$ & 0.016 \\
\hline Protein, g/dL & $4.9 \pm 0.071$ & $3.6 \pm 1.64$ & $* 0.00$ \\
\hline LDH, U/L & $1047 \pm 1107$ & $831.2 \pm 985$ & 0.14 \\
\hline Cell count, cell/mL & $2131.8 \pm 2791.4$ & $2207.5 \pm 5984.9$ & 0.91 \\
\hline ESR & 68 & 45 & $* 0.02$ \\
\hline Cell predominance & Lymphocytes & Lymphocytes, polymorph & \\
\hline
\end{tabular}

$P$ value of $<0.05$ was considered to be statistically significant.

Table 3:Comparison of GeneXpert results with culture as gold standard.

\begin{tabular}{|c|c|c|c|c|}
\hline \multirow[t]{3}{*}{ GeneXpert TB } & \multicolumn{4}{|l|}{ Culture } \\
\hline & \multicolumn{2}{|c|}{ Pleural $(n=75)$} & \multicolumn{2}{|c|}{ Sputum $(n=125)$} \\
\hline & Positive & Negative & Positive & Negative \\
\hline Positive & 11 & 8 & 67 & 6 \\
\hline Negative & 6 & 50 & 2 & 50 \\
\hline
\end{tabular}

Table 4: Sensitivity, specificity, PPV and NPV values of GeneXpert with culture as gold standard.

\begin{tabular}{|l|l|l|l|l|}
\hline Specimen type & Sensitivity & Specificity & PPV & NPV \\
\hline Overall & 80.9 & 85.7 & 74.8 & 89.2 \\
\hline Pleural & $64.7 \%$ & $86.2 \%$ & $57.9 \%$ & $89.2 \%$ \\
\hline Sputum & $97.1 \%$ & $89.2 \%$ & $91.7 \%$ & 96.2 \\
\hline
\end{tabular}

Table 5: Correlations of ADA Level (u/l) with gene expert and lymphocyte count with MTB.

\begin{tabular}{|l|l|l|}
\hline Specimen type & ADA Level(u/l) & Lymphocyte count \\
\hline $\begin{array}{l}\text { Positive } \\
\text { GeneXpert }\end{array}$ & $\mathrm{R}=0.89$ & \\
\hline Positive MTP & $\mathrm{P}=0.05$ & $\begin{array}{l}\mathrm{R}=0.91 \\
\mathrm{P}=0.05\end{array}$ \\
\hline
\end{tabular}

N.B Correlation coefficient $(\mathrm{r})$ defined as negligible $(<0.3)$, weak $(0.3-0.5)$, moderate $(0.5-0.7)$, high $(0.7-0.9)$, very high $(>0.9)$.

\section{DISCUSSION}

The standard diagnosis of PTB is based on M. tuberculosis isolation or direct observation of AFB yet, other diagnostic methods with shorter duration and acceptable sensitivity and specificity are essential.[8,9] Rapid diagnosis of
P-TB from sputum by the GeneXpert MTB/RIF method using the PCR is unavailable in low income countries due to the high costs of this method. [10]

In present study patients with $\mathrm{TB}$ reported more males than females this in agree with 
Annals of International Medical and Dental Research

E-ISSN: 2395-2822 | P-ISSN: 2395-2814

Vol-8, Issue-2 | March-April 2022

DOI: $10.53339 /$ aimdr.2022.8.2.8

Page no- 43-51 | Section- Research Article (Radiodiagnosis)

Khushbu, et al 2016.[11], and Kumari et al 2016 who reported $41(68.3 \%)$ males and 19 $(31.7 \%) .[12]$

Patients with TB-PLE tend to be younger than patients with P-TB. In one recent series from Qatar and Agha et al 2015, the mean age of 100 patients with TBP-E was 31.5 year,[13] thus, the age of patients in present study matched the age reported to be susceptible to tubercular pleurisy in previous series.[11]

Significantly increased ADA activity in the serum of pulmonary TB and tubercular pleural effusion patients compared to healthy controls and non-TB pleural effusion is due to activation of cell mediated immunity (delayed hypersensitivity) to Mycobacterium tuberculosis antigen.

In tuberculosis there are increased numbers of T-lymphocytes and macrophages in pleural fluid which may be associated with highly elevated ADA activity in such patients. In pathological conditions, the clearance capacity of lungs is decreased leading to increased numbers of cells in pleural fluid and the recirculation of activated $\mathrm{T}$ cells may cause a high serum ADA activity in patients with pulmonary disease.[14]

Many studies have suggested that pleural fluid adenosine deaminase (pfADA) is useful in the diagnosis of TB-PLE.[15] The merits of using pfADA include its low cost, short turn around time, and high sensitivity and specificity.

In the present study, a few cases with P-TB showed elevated ADA activity in spite of sputum negative for tuberculosis suggesting that serum and pleural fluid ADA activity is a sensitive, quick and easy marker for the diagnosis and patients can be started on Empirical treatment while waiting for other test reports to be positive. Castro et al studied 410 cases of lymphocytic pleural effusion. The negative predictive value of the ADA test was very high (99\%) similar to the present case.[17]

Pleural ADA is significantly higher than serum ADA levels in both TB-PLE ( $\mathrm{p}$ 0.002) and nonTB-PLE $(p<0.005)$ pleural effusions, suggesting a localized intra-pleural production. in accordance with the study of Sonone et al, to avoid pleural biopsy in as much as $82 \%$ of patients as certain diagnosis of TB.[14]

Against our study, Alpana et al found that On pleural fluid examination, except for ADA levels none of the variables showed a significant difference.[19] So, pleural fluid ADA level is very helpful test to rule out a tubercular etiology of pleural effusion. And can help differentiate tubercular etiology from non-tubercular.The usefulness of ADA was evaluated with a cut-off value of $30.0 \mathrm{U} / \mathrm{L}$ in serum and $100.0 \mathrm{U} / \mathrm{L}$ in pleural fluids to diagnose P-TB and TB-PLE.

Total count greater than $10,000 / \mathrm{mm} 3$ similar to light's observation. 90\% of TB effusions and most of malignant effusions had lymphocyte predominance. Our result was similar to the study done by Valdes L et al where they have encountered neutrophil predominant TB -PLE in only $6.7 \%$ of patients and only one malignant effusion had neutrophil predominant effusion (3\%).

The WHO endorsed Xpert@ MTB/RIF assay (Xpert [Cepheid, CA, USA]), which was initially approved for the diagnosis of pulmonary $\mathrm{TB}$, has now also been 
Annals of International Medical and Dental Research E-ISSN: 2395-2822 | P-ISSN: 2395-2814

Vol-8, Issue-2 | March-April 2022

DOI: 10.53339/aimdr.2022.8.2.8

Page no- 43-51 | Section- Research Article (Radiodiagnosis)

recommended for TB-PLE diagnosis including that of P- TB. 19$]$

In this study, we have evaluated the diagnostic ability of Gene Xpert as a simple bench top point of care diagnostic assay, overall sensitivity; specificity; PPV and NPV of GeneXpert were is comparable with other studies.[20,21] Sensitivity and specificity of GeneXpert in sputum assay in our study is $97.1 \%$ and $89.2 \%$ in agree with the study of Sharma et al., (96.9\% and 99.8\%).[22]In contrast with Previous studies showed that the Xpert MTB/RIFassay test has very low diagnostic sensitivity.[23]

Sensitivity and specificity of GeneXpert in pleuralfluid was $(64.7 \%$ \& 86.2\%), Other international studies showed lower sensitivity and little higher specificity on pleural fluid as $(25 \% \& 100 \%),(16 \%$ \& 100\%),(28.7\% \& 96.6\%) respectively. $[24]$

In agreement with our result for overall sensitivety $80.9 \%$ \&specificity $85.7 \%$, A more recent meta-analysis that evaluated the accuracy of Xpert_MTB/RIF in 1385 pleural fluid samples confirmed a low pooled sensitivity than serum(43.7\%; 95\% CI24.8\%; $64.7 \%$ ) and a high pooled specificity (98.1\%; 95\% CI95.3\%; 99.2\%) if culture for MTB was used as the reference standard.[25]

One of the possible reasons for the low sensitivity of PCR-based tests is that pleural effusions are thought to be due to a local inflammatory reaction and organism burden is low in pleural fluid,. Another possible explanation for the very low sensitivities in our study was the presence of inhibitory substances. Blood and other inhibitors, such as heparin or pus may interfere with cell lysis, inactivating DNA polymerase or interfering with nucleic acids. [26]

Forteen samples which were culture negative and GeneXpertpositive, the result of GeneXpert was very low or low positive as history of treatment with antitubercular therapy (ATT) cannot be ruled out with low bacterial load. PCR test amplifies any DNA, of live or dead bacilli. Therefore while diagnosing a person with active tuberculosis clinicians need to be very cautious using it as a sole method. Clear history of treatment with ATT is required to avoid false positive result. [20,27]

There was a significant positive correlation between MTB detected patients by Gene Xpert and ADA value $(\mathrm{r}=0.92, \mathrm{p}<0.05)$, and similarly significant positive correlation was also seen with MTB detected patients and lymphocyte count $(r=0.97, p<0.05)$ this is agree with similar study Ahmed et al in 2014 and Amarendra et al 2017.[1,28]

\section{CONCLUSIONS}

The conventional methods like culture, AFB and pleural biopsy although they considered greater diagnostic yield but insufficient criteria, so pADA has shown promising results in diagnosis of tuberculous pleural as supplementary biomarker with excellent specificity of gene expert in diagnosis of pleural TB effusion.

GeneXpert can be a useful diagnostic method in patients of suspected pulmonary tuberculosis either AFB smear negative or positive due to its rapidity and simultaneous detection of Rifampicin resistance especially beneficial in patient with MDR and HIV 
Annals of International Medical and Dental Research E-ISSN: 2395-2822 | P-ISSN: 2395-2814

Vol-8, Issue-2 | March-April 2022

DOI: 10.53339/aimdr.2022.8.2.8

Page no- 43-51 | Section- Research Article (Radiodiagnosis)

associated tuberculosis. Cost effectiveness of GeneXpert in low income countries like India with high prevalence of tuberculosis need to be done.

\section{Limitations}

Firstly, considering the wide variations in the cut off values mentioned for the ADA activity, it would be advisable that each laboratory or institute sets up its own standard ADA values.
Secondly, one of the important strength of the Xpert assay is its ability to detect the presence of Rifampicin resistance. The sensitivity and specificity of MTB/RIF assay to detect Rifampicin resistance in our study was not evaluated.

Thirdly, as number of samples present in this study is less, further studies with more number of samples need to be done.

\section{REFERENCES}

1. Shukla AK, Kajal NC, Malhotra B, Gupta S, Nishanth P, Singh A. Role of gene Xpert MTB/RIF assay in diagnosis of Tubercular Pleural Effusion. IntJCurResMedSci. 2017;3(5):105-10.

2. Mortazavi-Moghaddam SGR, Sharifzadeh GR, Rezvani MR. Pleural Fluid Adenosine Deaminase Values in Diagnosis of Tuberculous Pleural Effusion in South Khorasan Province. Zahedan J Res Med Sci. 2016;18(12):e5219.

3. Tay TR, Tee A. Factors affecting pleural fluid adenosine deaminase level and the implication on the diagnosis of tuberculous pleural effusion: a retrospective cohort study. BMC InfectDis. 2013;13(1):546.

4. Gopi A, Madhavan SM, Sharma SK, Sahn SA. Diagnosis and treatment of tuberculous pleural effusion in 2006. Chest. 2007;131(3):880-889. doi: 10.1378/chest.06-2063.

5. Pandey R, Tamrakar D, Jaiswal S, Sharma A, Koju S, Duwal SR. Serum Adenosine Deaminase: a novel biomarker tool for the diagnosis of tuberculosis. BiosciBiotechnol Res Asia. 2016;13(1):551-6.

6. Boloursaz M, Khalilzadeh S, Khodayari A, Hakimi S. Adenosine Deaminase Level as an Indicator for Differentiating Between Active Pulmonary Tuberculosis Infection and Other Pulmonary Infections. J Compr Ped. 2012;3(1):3-6.

7. Light RW. Update on tuberculous pleural effusion. Respirology. 2010;15(3):451-8. doi: 10.1111/j.14401843.2010.01723.x.

8. Shah I, Gupta Y. Role of molecular tests for diagnosis of tuberculosis in children. World health. 2015;12:13.

9. Agrawal M, Bajaj A, Bhatia V, Dutt S. Comparative Study of GeneXpert with ZN Stain and Culture in Samples of Suspected Pulmonary Tuberculosis. J Clin Diagn Res. 2016;10(5):DC09-DC12. doi:10.7860/JCDR/2016/18837.7755

10. Jobayer M, Shamsuzzaman S, Mamun KZ. Rapid Diagnosis of Pulmonary Tuberculosis From Sputum by Polymerase Chain Reaction. Arch Clin Infect Dis. 2014;9(2):1.

11. Khushbu T, Lal GM. Evaluation of ADA Activity in Pleural Fluid for Tuberculous Pleuritis. Int J Contemp Med Res. 2016;3(10):1-3.

12. Kumari RSP, Reddy BN, Vipula V. Role of adenosine deaminase in diagnosis of exudative type of pleural effusion. Int J Med Sci Public Health. 2017;6(2):28690.

13. Agha MA, El-Habashy MM, Helwa MA, Habib RM. Role of thoracentesis in the management of tuberculous pleural effusion. Egypt J Chest Dis Tuberc. 2015;64(1):97-102.

14. Kanchan KS, Santosh GV, Vishal MS, Leela GA, Niyogi NG, Joshi A. Study of Adenosine Deaminase Levels in Patients of Pulmonary Tuberculosis with and Without Pleural Effusion. IOSR-JDMS. 2014;13(1):2279-0853.

15. Garcia-Zamalloa A, Taboada-Gomez J. Diagnostic accuracy of adenosine deaminase and lymphocyte proportion in pleural fluid for tuberculous pleurisy in different prevalence scenarios. PLoS One. 2012;7(6):e38729. doi: 10.1371/journal.pone.0038729. 
Annals of International Medical and Dental Research E-ISSN: 2395-2822 | P-ISSN: 2395-2814

Vol-8, Issue-2 | March-April 2022

DOI: 10.53339/aimdr.2022.8.2.8

Page no- 43-51 | Section- Research Article (Radiodiagnosis)

16. Baba K, Hoosen AA, Langeland N, Dyrhol-Riise AM. Adenosine deaminase activity is a sensitive marker for the diagnosis of tuberculous pleuritis in patients with very low CD4 counts. PLoS One. 2008;3(7):e2788.

17. Jiménez Castro D, Díaz Nuevo G, Pérez-Rodríguez E, Light RW. Diagnostic value of adenosine deaminase in nontuberculous lymphocytic pleural effusions. Eur Respir J. 2003;21(2):220-4. doi: 10.1183/09031936.03.00051603.

18. Valdés L, Alvarez D, San José E, Juanatey JR, Pose A, Valle JM, et al. Value of adenosine deaminase in the diagnosis of tuberculous pleural effusions in young patients in a region of high prevalence of tuberculosis. Thorax. 1995;50(6):600-3. doi: 10.1136/thx.50.6.600.

19. Lawn SD, Mwaba P, Bates M, Piatek A, Alexander $\mathrm{H}$, Marais BJ, et al. Advances in tuberculosis diagnostics: the Xpert MTB/RIF assay and future prospects for a point-of-care test. Lancet Infect Dis. 2013;13(4):349-61. doi: 10.1016/S1473-3099(13)700082.

20. Barnard DA, Irusen EM, Bruwer JW, Plekker D, Whitelaw AC, Deetlefs JD, et al. The utility of Xpert MTB/RIF performed on bronchial washings obtained in patients with suspected pulmonary tuberculosis in a high prevalence setting. BMC Pulm Med. 2015;15(1):103.

21. Khalil KF, Butt T. Diagnostic yield of Bronchoalveolar Lavage gene Xpert in smearnegative and sputum-scarce pulmonary tuberculosis. J Coll Physicians Surg Pak. 2015;25(2):115-8.

22. Sharma SK, Kohli M, Yadav RN, Chaubey J, Bhasin $\mathrm{D}$, Sreenivas $\mathrm{V}$, et al. Evaluating the diagnostic accuracy of Xpert MTB/RIF assay in pulmonary tuberculosis. PloS one. 2015;10(10):e0141011.

23. Denkinger CM, Schumacher SG, Boehme CC, Dendukuri N, Pai M, Steingart KR. Xpert MTB/RIF assay for the diagnosis of extrapulmonary tuberculosis: a systematic review and meta-analysis. Eur Respir J. 2014;44(2):435-46. doi: 10.1183/09031936.00007814.

24. Friedrich SO, von Groote-Bidlingmaier F, Diacon AH. Xpert MTB/RIF assay for diagnosis of pleural tuberculosis. J Clin Microbiol. 2011;49(12):4341-4342. doi:10.1128/JCM.05454-11

25. Al-Soud WA, Jönsson LJ, Râdström P. Identification and characterization of immunoglobulin $\mathrm{G}$ in blood as a major inhibitor of diagnostic PCR. J Clin Microbiol. 2000;38(1):345-350. doi:10.1128/JCM.38.1.345-350.2000

26. Huo Z-y, Peng L. Is Xpert MTB/RIF appropriate for diagnosing tuberculous pleurisy with pleural fluid samples? A systematic review. BMC Infectious Diseases. 2018;18(1):284.

27. Van Rie A, Page-Shipp L, Scott L, Sanne I, Stevens W. Xpert( $\left({ }^{\circledR}\right)$ MTB/RIF for point-of-care diagnosis of TB in high-HIV burden, resource-limited countries: hype or hope? Expert Rev Mol Diagn. 2010;10(7):937-46. doi: 10.1586/erm.10.67.

28. Srwar A, Akhtar R, Ahmad I, Mukhtar MN, Imran S, Akbar $\mathrm{H}$, et al. Rapid detection of Mycobacterium tuberculosis and Rifampicin Resistance in extra pulmonary samples using Gene Xpert MTB/RIF assay. IOSRJDMS. 2014;13(11):50-3.

Source of Support: Nil, Conflict of Interest: None declared 